\title{
Teratoma renal, aportación de un caso y revisión de la literatura
}

\author{
E. Mallén Mateo, C. Sancho Serrano, Mã J. Gil Sanz, Á. Borque Fernando, \\ D. Yagüe Romeo*, L.Á. Rioja Sanz
}

Servicio de Urología. *Servicio de Radiodiagnóstico. Hospital Universitario Miguel Servet. Zaragoza.

Actas Urol Esp 2005; 29 (5): 516-518

\section{RESUMEN}

TERATOMA RENAL, APORTACIÓN DE UN CASO Y REVISIÓN DE LA LITERATURA

Objetivo: Reportar un caso inusual de tumor renal.

Métodos: Mujer de 42 años que debutó clínicamente con masa lumbar izquierda, se diagnosticó mediante TAC de masa renal, realizándole nefrectomía total. El estudio anatomopatológico confirmó teratoma renal.

Resultados: Después de tres años de seguimiento la paciente está asintomática.

Conclusión: El teratoma renal es un tumor muy infrecuente pero de buen pronóstico.

Palabras clave: Enfermedad renal. Teratoma renal. Neoplasia extragonadal.

\section{ABSTRACT}

RENAL TERATOMA, CASE REPORT AND REVIEW OF THE LITERATURE

We report a case of intrarenal teratoma in a 39-year-old female patient. The clinical course after three years of follow-up has been satisfactory, finding the patient totally asymptomatic.

Extragonadal teratoma occurs predominantly along the median line of the body.Intrarenal teratoma is extremely rare;however, it should be distinguished from other cystic lesions.

Keywords: Kidney diseases. Renal teratoma. Extragonadal neoplasia.

$L^{\infty}$ os teratomas renales son extremadamente raros, sobretodo en la edad adulta. Existen numerosos casos de teratomas localizados en retroperitoneo, con predominio de presentación en la infancia. Son pocos los casos de teratomas localizados en riñón. Reportamos un caso de teratoma con localización renal en mujer adulta.

\section{CASO CLÍNICO}

Paciente mujer de 39 años sin antecedentes personales de interés, que consultó por dolor en flanco izquierdo. En la exploración física se objetivó una gran masa en región lumbar.

La ecografía abdominal nos describía una masa retroperitoneal de $15 \times 8 \mathrm{~cm}$. El T.A.C reveló gran masa retroperitoneal izquierda, que comprendía al riñón y parecía depender de su porción capsular, con componente mixto-quístico, desde polo inferior renal hasta pelvis por delante de la bifurcación aortoiliaca. Sin signos de infiltración.

Sin contraindicación quirúrgica se decidió exéresis de la masa, intraoperatoriamente se observó una gran masa retroperitoneal que incluía riñón izquierdo, con componente quístico, se realiza exéresis completa de dicha masa junto con inevitable nefrectomía izquierda.

La anatomía macroscópica describía a nivel del polo renal inferior neoformación de 20 × 14 × $9 \mathrm{~cm}$ con componente sólido y quístico (Fig. 1). La microscopia electrónica confirmaba, teratoma quístico mucinoso con áreas sólidas de trasformación a tumor carcinoide, con el resto de parénquima renal sin otras particularidades, la positividad para cromogranina, enolasa neuronal y sinaptofusina expresan la neurosecreción de dicho tumor (Fig. 2). 


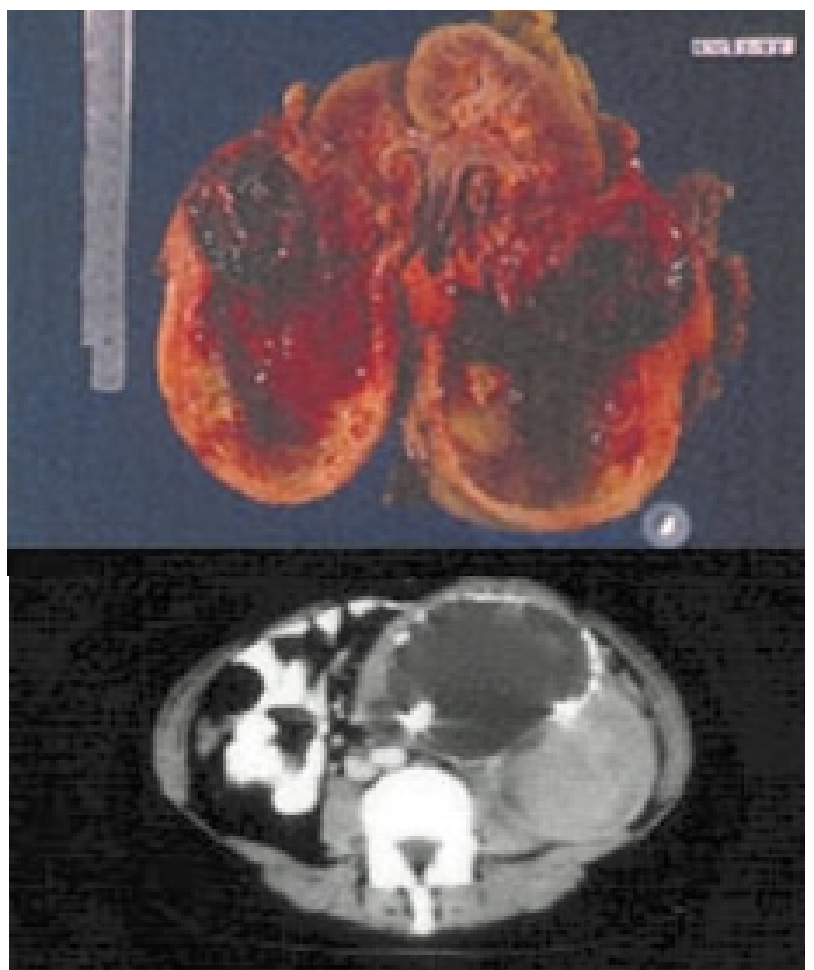

FIGURA 1. En polo renal inferior neoformación de $20 \times 14$ $x \mathbf{c m}$, con componente sólido y quistico.

La evolución posterior tras tres años de seguimiento ha sido satisfactoria encontrándose la paciente totalmente asintomática.

\section{DISCUSIÓN}

El teratoma extragonadal ocurre predominantemente a lo largo de la línea media ${ }^{1}$.
El riñón es uno de los sitios menos comunes de localización de teratomas y otros tumores germinales. Pero deben de ser considerados en el diagnóstico diferencial de masas abdominales en niños y adultos ${ }^{2}$.

El teratoma tiene componente sólido y quístico, son relativamente avasculares, por lo que pueden causar alguna confusión en el diagnóstico y ser confundidos con quistes simples. Pueden contener una amplia variedad de tejidos celulares representando las tres capas germinales ${ }^{1}$. El origen de los tumores neuroendocrinos renales es muy debatido porque en el riñón no se han descrito células neuroendocrinas y siempre ha de descartarse un primario extrarrenal. Entre las hipótesis barajadas, la de una stem cell y la del atrapamiento de restos de la cresta neural son las preferidas.

Son tumores normalmente benignos, aunque se han descrito metástasis en teratomas bien diferenciados.

Normalmente ocurre en niños, en la literatura se reporta el primer caso en 1934 por Mc Curdy en un niño de siete años con síndrome de PruneBelly ${ }^{3}$. Aunque en la edad adulta son extremadamente raros en 1976 Kojiro et al. describirían el primer caso en un adulto, varón, de 40 años ${ }^{4}$.

Pocos años más tarde, en 1979 Dische aportaría el primer caso de teratoma renal en un paciente con riñón en herradura ${ }^{5}$.

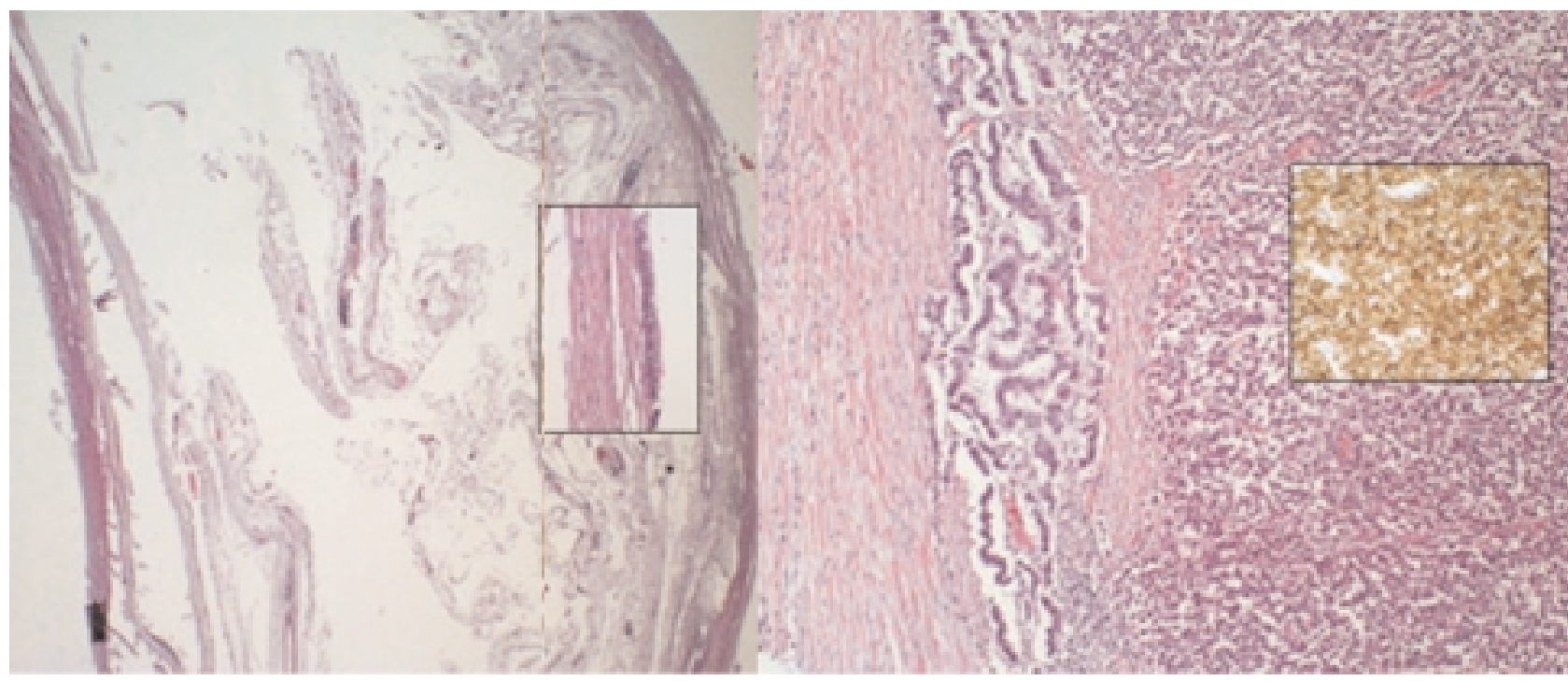

FIGURA 2. Tumor mixto con área sólida carcinoide y área mucinosa, rodeadas por cápsula fibrosa. En detalle positividad para Cromogranina del tumor carcinoide. Detalle histológico de área quística tapizada por epitelio mucinoso. 
Hasta la actualidad han sido descritos 15 casos, 8 de ellos eran varones. Las edades variaban dentro de un amplio rango de edad desde el nacimiento hasta 71 años, con claro predominio de presentación en la infancia.

En el estudio histológico dos de los casos, al igual que el presentado por nosotros, se asociaba con tumor carcinoide. De los 15 casos, tres presentaron metástasis, dos con elementos del saco vitelino en la histología y otro con restos embrionarios. Pero hay que señalar que tras la extirpación de dichas lesiones no hubo recurrencia ${ }^{6}$.

Tras el análisis de la literatura, podemos observar que estamos ante una patología renal excepcional, pero que debemos de tener en cuenta en el diagnóstico diferencial de toda masa abdominal, sobretodo si se presentan en la infancia. Al tener la mayoría un componente quístico conviene diferenciarlos de quistes simples renales ${ }^{7}$.

Aún siendo tumores normalmente benignos está descrita su capacidad de metastatizar. Así mismo, cuando se asocia a tumor carcinoide puede empeorar su pronóstico, por lo que está totalmente justificado su exéresis completa.

\section{REFERENCIAS}

1. GlazierWB, Lytton B, Tronic B. Renal teratomas: case report and review of the literature. J Urol 1980;123:98-99.

2. Otani M, Tsujimoto S, Miura M, Nagashima Y. Intrarenal mature cystyc teratoma associated with renal dysplasia : case report and literature review. Patho Int 2001;51:560-564.

3. Prasad SB. Intrarrenal teratoma. Postgrad Med J 1983;59: 111-112.

4. Kojiro M, Ohishi H, Isobe H. Carcinoid tumor occurring in cystic teratoma of the kidney: a case report. Cancer 1976; 38:1636.

5. Dische MR, Johnston R. Teratoma in horses kidneys. Urology 1979;13:435-438.

6. Singer AJ and Anders KH: primary teratoma of the kidney. Urology 2001;58:1056-1057.

7. Ishii C, singleton EB, Gresik MV. Computerized Tomography demostration of an intrarenal teratoma. J Urol 1987;137: 272-273.

Dra. E. Mallén Mateo

S. Antonio $\mathrm{M}^{\mathrm{a}}$ Claret 66; $2^{\mathrm{o}} \mathrm{I}$

50005 Zaragoza

(Trabajo recibido el 4 octubre de 2004) 